\title{
The Challenges for Food Safety in China
}

Current legislation is unable to protect consumers from the consequences of unscrupulous food production

\section{Bian Yongmin}

\section{OpenEdition}

\section{Journals}

Édition électronique

URL : http://journals.openedition.org/chinaperspectives/819

DOI : 10.4000/chinaperspectives.819

ISSN : 1996-4617

Éditeur

Centre d'étude français sur la Chine contemporaine

\section{Édition imprimée}

Date de publication : 1 mai 2004

ISSN : 2070-3449

Référence électronique

Bian Yongmin, "The Challenges for Food Safety in China », China Perspectives [En ligne], 53 | MayJune 2004, mis en ligne le 24 juin 2008, consulté le 28 octobre 2019. URL : http://

journals.openedition.org/chinaperspectives/819; DOI : 10.4000/chinaperspectives.819

Ce document a été généré automatiquement le 28 octobre 2019

(C) All rights reserved 


\title{
The Challenges for Food Safety in China
}

\author{
Current legislation is unable to protect consumers from the
} consequences of unscrupulous food production

\section{Bian Yongmin}

1 After a long time fighting food shortages, China has been self-sufficient in food since 1995'. But in the Action Plan on Food Safety published by China's Ministry of Health $(\mathrm{MOH})$ on August 14th $2003^{2}$, the government classes the following current risks relevant to food safety in China as "very serious": 1) Food-induced illnesses remain the supreme danger for public health; 2) New biological and chemical pollutants in food; 3) New food technologies and materials (such as transgenic food) raise new challenges; 4) The capacity for self-management among food producers is weak; 5) Food terrorism; 6) Slow food safety supervision by government organs. A number of scandals during 2002 illustrate the severity of the situation ${ }^{3}$. The government is facing pressure from consumer demand for safe food ${ }^{4}$. Moreover, since China's accession to the World Trade Organisation (WTO), food imports and exports have increased, and disputes about food safety have arisen between China and its trading partners. The European Union has refused Chinese food many times for reasons of safety ${ }^{5}$. These refusals not only cause huge losses of goods, they also discourage future transactions. How to ensure food safety has as a consequence become a government priority.

Historical background

2 In 1965 China promulgated its first food safety law-the Regulations on the Administration of Food Hygiene (Trial Implementation). These regulations mainly referred to state-owned food producers. The main concern at this time was the security of the food supply rather than the safety of the food itself, and came shortly after the terrible Three-Year Famine ${ }^{6}$. These first regulations failed however, due to the collapse of the legal system in China in the decade following?

3 Before the end of 1970s, China's economy was strictly planned and controlled by the state. All food production factories were owned and controlled by the state, and observed some simple food standards. There were few food safety problems because 
most food was produced using traditional methods without heavy use of chemical fertilisers, pesticides and additives. Profits were not the aim food producers because the entire food production chain, from the materials, equipment and technologies, to distribution and sale, were centrally planned and controlled by the state. Food safety accidents were occasional, but did not damage the overall image of food safety.

Following the Cultural Revolution and with the economic reforms at the end of 1970s, many new laws and regulations were renewed or enacted. In 1979 the Regulations on the Administration of Food Hygiene was drafted. They were based on the 1965 Regulations and took into account the new economic situation. Three years later, the new regulations were replaced by a new version in 1982. This was the Food Hygiene Law. This was also a trial implementation to accommodate the situation of continuing economic reforms was still underway and frequent policy changes. The revised and current Food Hygiene Law was implemented in 1995.

The government is trying to use of chemical fertilizers and pesticides

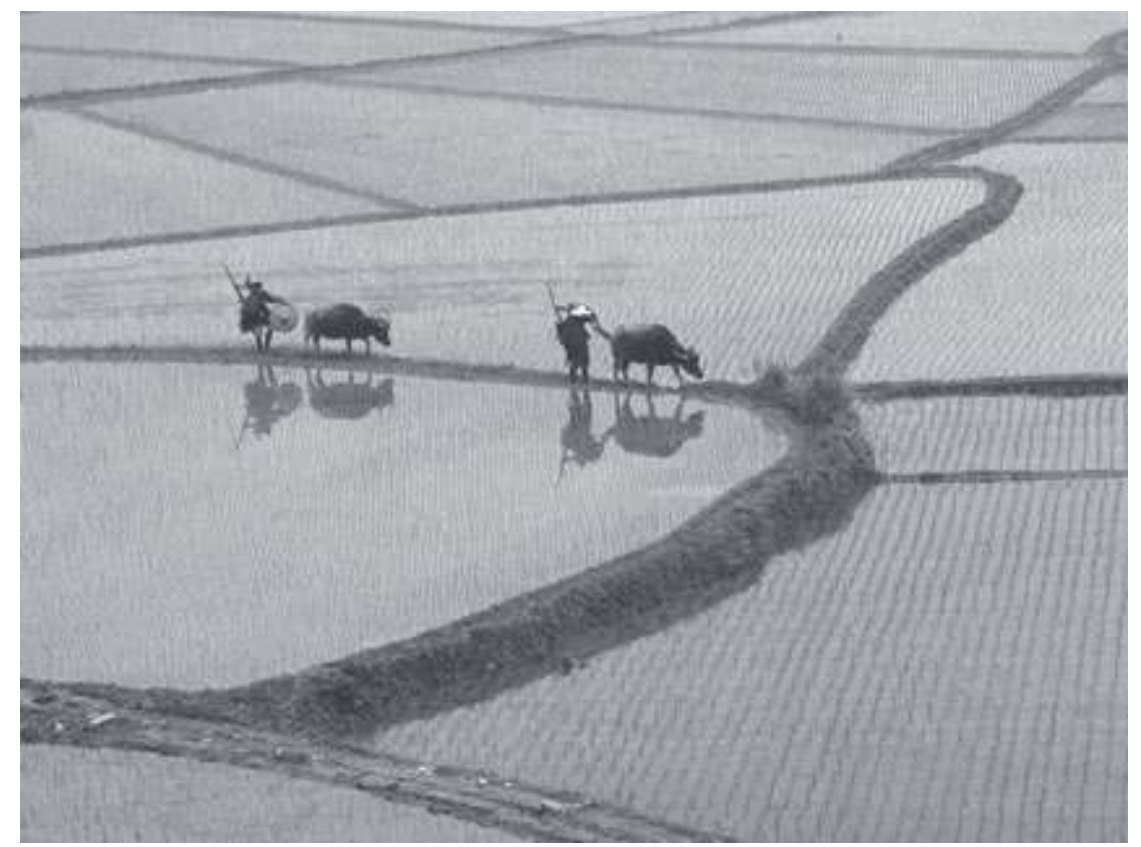

(c) Imaginechina

This paper will outline China's current legislation on food safety and evaluate its role as well as problems arising from it. We will look first at the law on the safety of "straight" food, and then at that on genetically modified (GM) food. A commentary on the enforcement of food safety law will follow and on the implications of China's experience for other developing countries.

Current legislation

The 1995 Food Hygiene Law forms the basis of the legal framework for food safety in China. Ironically perhaps, neither the 1995 Food Hygiene Law nor its predecessors provide a definition for "food hygiene". In the 1982 Food Hygiene Law the main concerns with regard to hygiene focused on rotten or dirty food or food capable of causing poisoning, or food processing that was not clean. However, the scope of the 1995 Food Hygiene Law is not limited only to food hygiene problems; it also covers 
many safety issues, such as food made with new materials, food in hospitals, food for infants ${ }^{8}$ etc.

The 1995 Food Hygiene Law

7 The 1995 Food Hygiene Law, promulgated by the National People's Congress, consists of 57 articles that cover general principles, food hygiene, food additives, packaged and containers of food, the enactment of regulations and hygiene standards on food, the administration of food hygiene, the supervision of food hygiene, penalties, and miscellaneous clauses including definitions. It adds 12 new articles to the 1982 Food Hygiene Law, and makes clear stipulations on the authority responsible for the administration of food hygiene ${ }^{9}$, the supervision of food hygiene by NGOs and individuals, the production of food, food that may not be produced, the absence of drugs in food, and on food for military and the services, etc. Seven new requirements state that ${ }^{10}$ :

- the layout of equipment and the processing methods should be reasonable;

- food containers must always be clean;

- the instruments for storage, shipment, loading and unloading must be safe and do not constitute a hazard;

- ready-to-eat food must be packed using materials that are clean and safe;

- the workers must wash their hands and put on clean clothes and headwear before producing or selling food;

- the water used must meet the standards set by the state; and

- the wash and disinfectant products used must be safe for human consumption and use.

8 The above are all crucial to ensuring the safety of an end product, but it is disputable whether these requirements are sufficient, or even exhaustive. For example, Article 8 (4) provides that ready-to-eat food should be packed with materials that are clean and safe for use: but no mention is made of the packaging used for ready-made food. This is quite typical of the articles contained in 1995 Food Hygiene Law, which covers only very basic practices.

9 Reference to planting and breeding, as these have relevance to food hygiene, is absent. So the law does not take a from-land-to-table approach. The inclusion of certain ingredients in food is illegal only when the ingredients affect the nutrition or hygiene of the food. So to mix a second grade rice with a top grade rice and sell the mix as top grade rice is not illegal under this law because both may be nutritious and hygienic. of course rice sold in such a way is illegal according to other laws, such as contract law. The method of enumeration adopted in this law to provide rules in a few key articles barely covers the extent and requirements of actual practice.

The 1995 Food Hygiene Law did not establish a system to deal with major food safety incidents, such as the outbreak of bird flu in China in the spring of 2004. Although the government quickly enacted a series of orders upon the occurrence of the bird flu, it remains unclear in law what would be required were another food safety incident to occur of a similar nature or on a similar scale.

Other regulations

11 Many food hygiene regulations were formulated in accordance with the 1995 Food Hygiene Law, which generally covers the following five areas: 1) food and raw materials, including administrative measures on food additives, transgenic food, milk, egg, meat and related products thereof, aquatic products, food made from new resources ${ }^{11}$, etc.; 2) food production and processing, which focuses for example on food 
disinfection; 3) food packaging, containers and equipment; 4) supervision and administrative penalties; 5) food inspection and testing.

It is very difficult to evaluate these regulations and their effectiveness in practice. Regulations that can be enacted by ministries are called guizhang. The administrative organs would enact new guizhang in order to deal with a new problem, but without checking carefully whether they were in agreement with effective laws or regulations enacted by the same administrative organ or by other administrative organs with jurisdiction in the same area. Thus, conflict among guizhang provisions is not rare.

Standards

The system of food hygiene standards is complicated. There are basically two categories of food hygiene standards-compulsory and voluntary. Most compulsory standards are established by the state; however, local government has the right to formulate local standards that do not conflict with national standards, or when there are no national standards.

When the government formulates a compulsory standard, it refers to foreign and international standards, such as the food code developed by Codex Alimentarius founded jointly by the Food and Agriculture Organisation and the World Health Organisation (Codex). But referring to the Codex does not mean that China is adopting the Codex. The level of protection depends to a large extent on the capacities of Chinese producers, especially with regard to their technical and financial capabilities, and trade interests of the state. In the 1980s, the majority of food producers were either unable or could not afford to produce food that met Codex standards.

15 Trade interests also play a role in determining the level of standards. For food for which China is mainly a net exporting state, the government is inclined to set a low standard that is easy for exporters to reach. Up to 2000 only $14.6 \%$ of food hygiene standards met those of the Codex ${ }^{12}$. Before entering the WTO, China made many adjustments to laws and standards in accordance with the provisions of the WTO. In the field of food hygiene standards, the government reviewed 464 standards and identified 1,379 issues $^{13}$. It made huge modifications, raising standards, especially those on the limits of pesticide residues, $85.4 \%$ of which now meet Codex requirements ${ }^{14}$. In addition, $81 \%$ of the standards on pollutants met Codex standards ${ }^{15}$. On the other hand, where Chinese food producers are capable of producing very safe food, or areas in the food industry where China is mainly a net import market, the government sets food standards even higher than those of the Codex.

Both the government and NGOs, i.e., various chambers of commerce which, according to the Chinese law, are non-governmental organisations, can recommend voluntary standards to food producers. These standards focus on many areas of food. Some of them relate to food safety, which may help food producers increase their share in domestic or export food markets. With the improvement of technology and financial ability, more and more food producers adopt many voluntary standards which may lead to better market success.

17 Among all the voluntary standards, the Green Food programme deserves much attention. The green food programme was launched by the Ministry of Agriculture (MOA) in 1992. Two categories of green food, AA and A, are defined by it. AA green food has the same standard for organic food. For example, GM ingredients are not permitted to be used in the production of AA green food. But as much of the land in China is heavily polluted with pesticides or other pollutants, it is not only expensive but also 
very difficult to produce. Category A green food was created to provide safe food based on the reality of China's natural environment. A green food is of a higher standard than normal food but lower than AA green food or organic food. For example, only limited amounts of pesticide and chemical fertilisers may be used in crop elevation in order to be considered "safe" without affecting yield. The environment, including the land, air and water, where crops are planted or animals live should also meet certain conditions. The green food programme did not develop well in its first few years. Yet, with the export of "normal" food having to meet safety requirements and consumers becoming more aware and more cautious about food safety, green food has become more popular ${ }^{16}$. Growing exports of green food motivated the government to promote the expansion of green food production ${ }^{17}$.

The development of a green food industry may have implications for the agricultural policies of other developing countries. Organic food is too expensive for most consumers, even for consumers in developed countries. It cannot therefore be the main direction for the development of agriculture. On the other hand, the health risks associated with the heavy use of chemical fertilisers and pesticides are clear. Green food is a compromise. The cost to produce it is not too high, while the use of chemical fertilisers and pesticides is permitted but heavily restricted to ensure yield and a guaranteed level of food safety.

Genetically modified food

Chinese scientists began studying transgenic technology in the early $1980 \mathrm{~s}^{18}$. They convinced senior Chinese leaders of the potential for genetic modification in agriculture ${ }^{19}$ when China was still struggling with food shortages. In the early 1990 s the first transgenic plant, tobacco, was planted in several large areas. At that time the planting of transgenic tobacco in China was carried out on an unprecedented scale for transgenic plants in the world ${ }^{20}$. Hebei province trial planted a transgenic cotton with seeds provided by the Monsanto Corporation in $1995^{21}$. Later two bio-technology joint ventures with Monsanto were set up in Hebei and Anhui provinces. Now in China a total ten GM plants are being trialled ${ }^{22}$. and six may be produced commercially-two kinds of cotton, two kinds of tomato, pimiento and an ornamental named Morning Glory ${ }^{23}$. In 2001 about 600 thousand hectares were planted with GM organisms (GMO) ${ }^{24}$. The decisions to develop and plant GMOs were made solely by the government with no consultation with the public or with academia. 
Workers engaged in the production or sale of foodstuffs are legally required to cover their hair

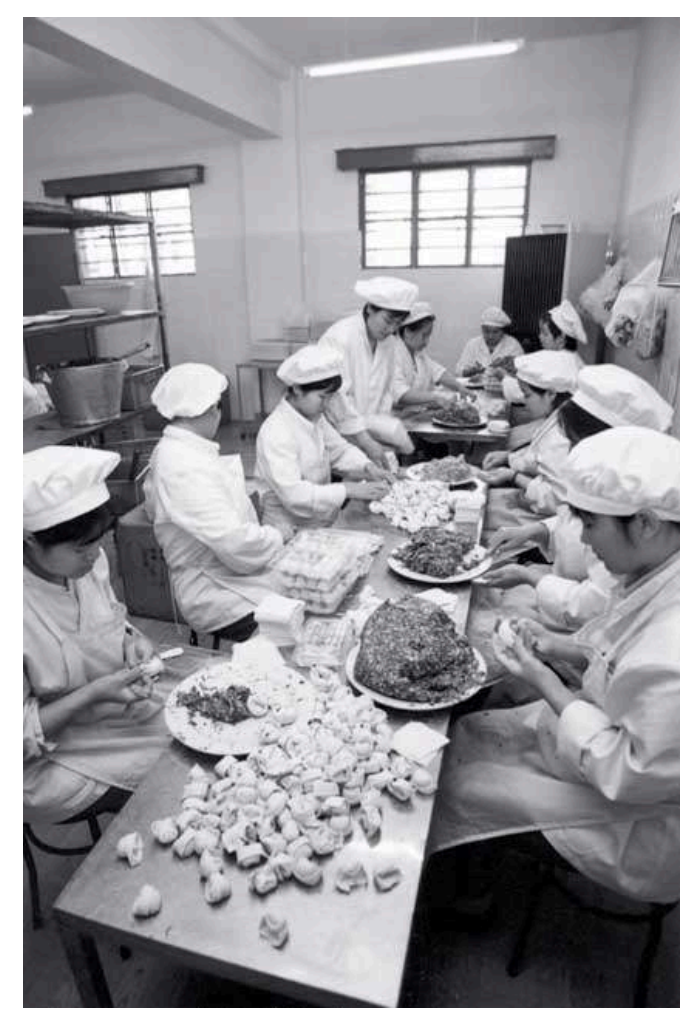

(c) Imaginechina

21 In 1993 the former State Science and Technology Commission (now the Ministry of Science and Technology) promulgated the Administrative Regulations on the Safety of Genetic Engineering, China's first biosafety-related regulations on genetic engineering. According to Article 1, the purposes of the regulations were to promote research and development in genetic modification, strengthen safety management, protect public health and the health of personnel engaged in genetic modification, prevent environmental pollution, and maintain ecological balance. It contains no provision for the control over transgenic product imports. GM foods were imported into china as normal food before 2002 .

The importation of GM food into China has increased year on year since $1996^{25}$. Enormous imports of American soybeans had a serious impact on Chinese farmers whose livelihood depends on soybean production ${ }^{26}$. It is a foreseeable result of China's entry into the WTO, that the importation of US-produced GM foods will continue to increase. With more and more GM food finding its way onto the tables of consumers, the problem of safety has been raised. Hence the government has enacted regulations to administrate, inter alia, the safety of imported GM food.

The regulations on the safety of GM food

In May 2001, The Regulations on the Administration of the Safety of Transgenic Agricultural Products (RASTAP) were promulgated. This is an important piece of legislation. All transgenic organisms, including plants, animals and micro organisms, whether imported to, exported from or transited through China, are subject to these regulations. According to an order of the State Council, RASTAP should enter into force on their date of promulgation ${ }^{27}$. This stipulation conflicts with the WTO's transparency rules. However, China was not a member of the WTO in May 2001. The United States 
was the first to show dissatisfaction with the way that RASTAP entered into force. Moreover, several of their provisions are ambiguous, in particular the evaluation of the safety of GMOs and their labelling, etc. Due to the above RASTAP did not enter into force on the date provided. As authorised by RASTAP, the MOA is responsible for the supervision and administration of the safety of GMOs. To enforce RASTAP, it enacted three sets of administrative measures in January 2002, which laid down detailed provisions on the safety, import and labelling of transgenic agricultural products. These measures became effective on March 20th 2002.

RASTAP and its measures, require the application of two methods to control the safety of transgenic products in international trade. First, Chinese importers or foreign exporters must apply for the transgenic products which may be imported later to be risk assessed. The Committee on the Safety of Agricultural Transgenic Organisms, which is affiliated to the MOA, is responsible for accepting this application, but may only do so twice a year. It must complete the assessment and respond to the applicant within nine months from the date of acceptance. Second, foreign exporters must label their transgenic products.

The three sets of measures were promulgated only two months prior to their effective date, causing many difficulties for importers of GMOs. Since risk assessments take nine months, it was impossible for importers to obtain the certificates required on the date of effect. The MOA had to make a transitional arrangement if it did not want the importation of GMOs, especially of soybean, to be halted. Therefore, on March 11th 2002 the MOA promulgated the Temporary Measures on the Administration of the Safety of Transgenic Agricultural Products (TMASTAP), according to which exporters of GMOs to China could apply for temporary certificates based on the documents issued in their own countries. TMASTAP's provisions were to expire on December 20th 2002. But "for technical reasons", their period of validity was extended to September 20th $2003^{28}$. On July 16 th 2003 , as stated by the MOA, again for technical reasons, this period was further extended to April 24th $2004^{29}$. With no new measures due to be published, this may be extended again.

The extent of trading interests in GMOs is considerable, and this explains the complexity of the GMO situation for China, the safety issues and the technology involved and the "technical reasons" claims made by the government. China is the biggest importer of soybeans. It imported 11.3 million tons of soya in $2002^{30}$. The trade value of soya between the United States and China is about US $\$ 1$ billion $^{31}$, and imports were expected to increase in 2003.

Enforcement Distorted administrative regime

In China there is no unified administrative organ with the authority to deal with all the issues relating to food safety. The MOH seems to be the most important organ for the governing of food safety, however, the MOA, the General Administration of Quality Supervision, Inspection and Quarantine (GAQSIQ), State Administration for Industry and Commence (SAIC), the State Environmental Protection Administration, the Ministry of Commerce (MOC, formerly the Ministry of Foreign Trade and Economic Cooperation), and the State Grain Administration, etc. also have jurisdiction over food issues, and/or supervise food producers. All these organs need to make detailed rules to tackle the issues in relation to their remit as well as within the scope of their respective powers. This is one reason why the 1995 Food Hygiene Law does not provide rules for planting and breeding, which are the responsibility of the MOA. The 1993 
Administrative Measures on the Safety of Transgenic Engineering is silent on trade of transgenic products as this is the remit of the Ministry of Commerce. In fact superfluous laws and regulations impair rather than enhance administration on food safety, and increase law enforcement costs, leaving food producers confused.

The involvement of so many authorities also cause problems of co-ordination from enactment to enforcement. The State Food and Drug Administration (SFDA) was instituted in 2003, with the mandate, inter alia, to integrate the administration and supervision of food safety, co-ordinate and organise investigation and impose penalties for serious violations of the law. The SFDA, however, has no teeth. Its powers relating to food safety are held by other ministries and agencies, while the SFDA itself is a semiministry. It has to co-ordinate among several ministries that have a higher administrative rank. When there is a conflict between these organs, the SFDA's decisions or opinions have no power and are unlikely to be executed.

So far its main progress made relating to food safety is its Food and Drug Safety Reassurance Programme, which demands that the MOA, MOH, GAQSIQ, SAIC, MOC, Ministry of Public Security (MPS) and the General Administration of Customs (CGA) should, within their respective scope, take steps to ensure food safety ${ }^{32}$. Yet it is almost impossible for the SFDA to successfully fulfil its co-ordination mission while so much overlap and separate jurisdictions remain.

For example, the $\mathrm{MOH}$ is entitled to grant a hygiene licence to a food producer, which is an essential measure to ensure food safety. Meanwhile, since 2002 GAQSIQ has been entitled to grant safety licences to food producers. In the MOH's view GAQSIQ's safety licences are unnecessary. After the MOA published several administrative measures relating to GMOs, the $\mathrm{MOH}$ also enacted The Administrative Measures on the Hygiene of GM Food. In fact, different organs often make their own plans relating to food safety, a situation where overlap or conflict is common.

31 Green Food is governed by the Centre of Green Food, affiliated to the MOA, while organic food is governed by the Centre of Organic Food, affiliated to the State Environmental Protection Administration ${ }^{33}$. The standards for Class AA green food are almost the same as those for organic food. In practice they compete with each other. This situation is wasteful of the resources of the state. Similarly, the safety of GM agricultural products is governed by the MOA, while the safety of normal food products is governed by the MOH.

32 This disordered situation will not easily be improved in the near future, because it relates to the redistribution of powers among different organs, a difficult move. Moreover, the administration of food is in itself especially difficult, particularly for China, with the world's largest population.

Inefficient administration through punishment

The main administrative work done by administrative organs is inspecting, several times a year, compliance with the Food Hygiene Law. The government does not attach enough importance to supervise the course of food production, or to help food producers increase their own capacity to ensure food safety. Most inspection work is about finding and punishing those food producers that break the law. The 1995 Food Hygiene Law does not prescribe the obligations of food producers to ensure food safety, yet penalties for breach are clearly stipulated. In 2002 such inspections covered $98 \%$ of 
food producers ${ }^{34}$. Those found to be involved in illegal activity were punished, fined or had their licences revoked, etc..

Other schemes or programmes which may work well to enhance food safety, such as taking a from-land-to-table approach, recalling of products not meeting standards, etc., and enhancing the traceability of food, etc. Penalties per se are neither an effective nor sufficient means of ensuring food safety. Solely announcing that the banning of certain pesticides will not guarantee food safety. Such pesticides must be recalled and destroyed to ensure their trade and use cannot continue.

Trade interests

The improvement of food safety is not only driven by safety concerns, but also by trade interests. Although this may not be true in all countries (it is the case in many countries), China seems to give more weight to trade. One purpose of the administration of food hygiene is to support food exportation because China produces more agricultural products than it needs ${ }^{35}$. In accordance with the Action Plan on Food Safety published by the MOH in September 2003, the government will "modify food safety regulations and standards from time to time to ensure that food hygiene regulations and standards meet the needs of food importation and exportation to protect consumer health" ${ }^{36}$. This approach may be typical in many developing countries.

The enforcement of GM safety regulations sheds light on China's concerns about trade interests in the field of food safety. After the promulgation of The Administrative Labelling Measures, the MOA published the first list of GMO to be labelled ${ }^{37}$. On this important list, only five categories of transgenic organisms, soya ${ }^{38}$, maize ${ }^{39}$, cotton ${ }^{40}$, tomato ${ }^{41}$ and rapeseeds ${ }^{42}$, are required to be labelled. Even for these five categories, not all products that include them must be labelled. Take soya as an example. According to this list, only five soya products required labelling. Soy milk, soy sauce and beancurd are not included. If safety were top priority, labelling of all food containing a certain percentage of GMO ingredients would be required. Soy sauce and beancurd are consumed extensively in China. Made using certain traditional Chinese methods, they are seldom imported from other countries. But if this is why they are not required to be labelled even if made using transgenic soya, the government's concern about GMOs seems disingenuous.

The 2002 Administrative Labelling Measures also have application to imported products. However, until the summer of 2003, the government did not inspect products in its domestic market for compliance with the labelling measures ${ }^{43}$. It was found that almost all transgenic soy oil producers breached this labelling rule before they were forced to comply through this inspection. But other GM food remained unlabelled in supermarkets up to the end of 2003.

In addition, the Administrative Labelling Measures did not clearly specify the minimum amount of any one transgenic ingredient in a product before this must be labelled. Thus it is not clear whether a mix of transgenic products with traditional products shall be labelled. Such mixing is more frequent in domestic products than in imported products.

Problems associated with rapid industrialisation

39 Although the government has done much to enforce and supervise the application of the food hygiene law, the food safety situation in China today remains unsatisfactory. In 2001 more than 19,000 people were poisoned in 611 food poisoning cases ${ }^{44}$. In 2002 
more than 11,000 people were poisoned in 464 food poisoning cases ${ }^{45}$. It is surprising that most poisoning cases occurred in families ${ }^{46}$ due to unsafe food products.

A large amount of unsafe foods are produced in areas that are no more rural but not yet urban, where the governance from both countryside and cities is weak. Following the process of industrialisation, cities expand as do the areas between the countryside and cities. However, governance by the municipal administrations has not yet expanded accordingly to the boundary of cities, on the other hand, the governance of villages is rapidly declining as farmers are losing their land. Many illegal food producers rent houses in these special areas to produce or process food and sell them in the city markets.

In the gray zones between town and country the authorities often lack authority

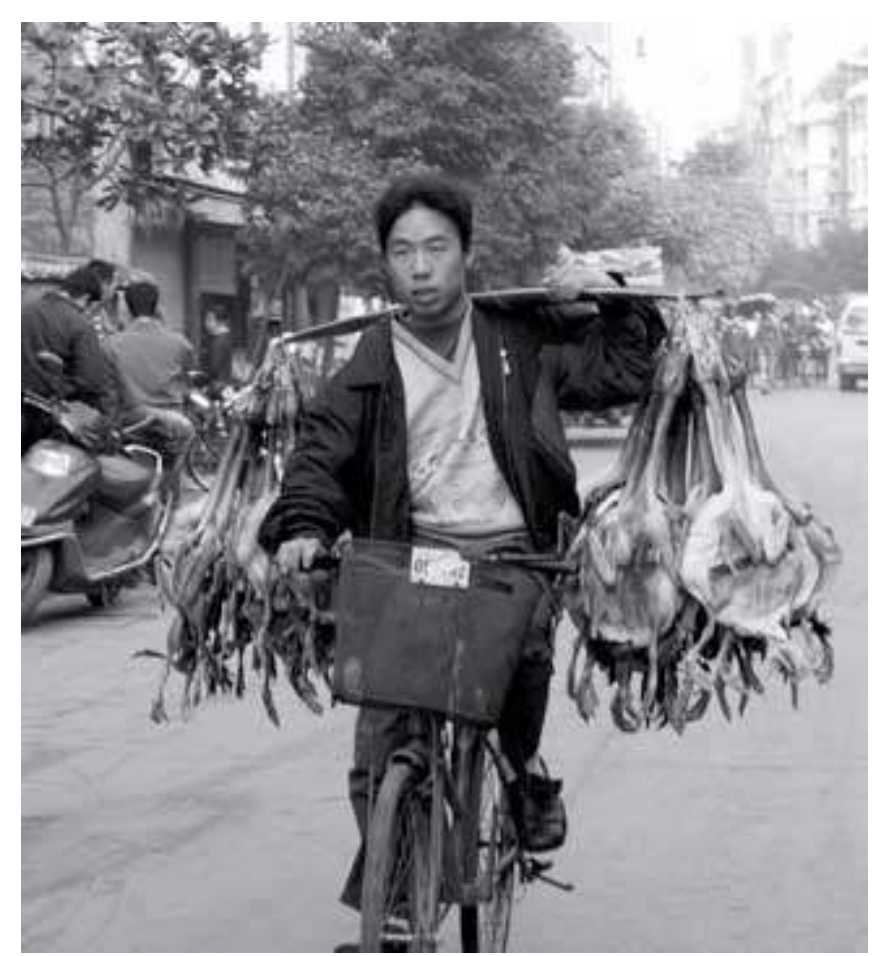

(c) Imaginechina

41 The case of "swill oil" (ganshui you) or "drain oil" (digou you) is typical ${ }^{47}$. It is said that in the suburbs of Peking alone, there may be more than 1,000 producers refining this kind of oil. Some producers may have been there for more than thirty years although the Peking Administration of Environmental Protection has cracked down many times. Moreover, to deal with one case of oil from swill, several organs have to act together, because the $\mathrm{MOH}$ is in charge of swill, the AEP is in charge of waste water and SAIC is in charge of business licences. This also explains how the problem of over-administration impedes the administration of food safety.

Now the SFDA has decided to enhance the administration in the grey zones between the cities and the countryside. But so far there are no special measures targeting administration in this jumbled area.

The MOH published a very ambitious Action Plan for Food Safety, which sets out a series of goals for food safety to be reached before or by $2008^{48}$. But it is highly 
questionable as to whether the $\mathrm{MOH}$ can bring food safety to all Chinese with its limited powers and under the current legal framework for food safety.

The 1995 Food Hygiene Law does not cover planting and breeding, which are the remit of the MOA. Nevertheless, the use of pesticides and chemical fertilisers in planting and animal medicines and hormones in breeding has caused many problems in agricultural products. China is the largest consumer of chemical fertilisers in the world ${ }^{49}$. Pesticides are heavily used in planting, of them $70 \%$ are very poisonous ${ }^{50}$. Several pesticides now forbidden in the European Union are still in use in China ${ }^{51}$. Pesticide residues on vegetables are so common and so dense that many hygiene experts suggest washing vegetables first then dunking them in hot water before cooking or eating them ${ }^{52}$. The power to administrate chemical fertilisers, pesticides and animal medicines is in the hands of the MOA, who is also the main user and beneficiary. The MOA should supervise the process of planting and breeding. The new Regulations on the Safety of Agricultural Products, which are still in their early stage of drafting, are to be enacted by the authority.

Although the chain from land to table has been cut into several administrative sections, the MOH seems decided to do its best in its own section. The 1995 Food Hygiene Law provides some important rules to ensure food safety in a simple way, something that easily causes confusion in their implementation. Now the MOH has determined to enact detailed regulations for the implementation of the 1995 Food Hygiene Law during 2004-5 $5^{53}$. A series of regulations and normative documents have been put on the legislative agenda by the $\mathrm{MOH}$, including The Administrative Rules on Sample Inspections of Food Hygiene, The Administrative Rules on Nutrition Labelling on Food, amending and publishing 316 food standards and enacting new standards such as standards on the maximum of residues of 19 chemical pollutants in various agricultural products and food, etc. ${ }^{54}$.

Over-administration, where several organs have the power to administrate the production and sale of food, will remain the most difficult problem in the implementation and supervision of food safety law and regulations. It is a major challenge for the state to establish a mechanism that will enable different bureaucracies to work efficiently and effectively in co-operation. Just like in the abovementioned swill case, if the relative organs cannot act at the same time, illegal producers will escape.

There were a total 382,737 food producing or processing entities in China in $2002^{55}$. Most were medium-sized or small, from which most food with safety problems originated. Although Chinese are becoming rich, the average income of urban residents is only 716 yuan (US\$86) a month ${ }^{56}$, which is much higher than that of rural residents. The large number of low income residents are a stable contingent and major consumers of poor quality food. "Swill oil" is targeted at such consumers. In 2002 the $\mathrm{MOH}$ inspected 505,084 food producers ${ }^{57}$ including cafeterias and restaurants nationwide, $13.68 \%$ of those inspected were found in breach of the law ${ }^{58}$. Given China's vast size, how to supervise so many small food producers is a massive challenge for the government. This is a common challenge for most developing countries, where most food producers are medium-sized or small businesses, lacking the ability and resources to implement self-management in food safety.

China began to regulate food safety immediately following the resolution of its food shortages. Yet China has not established a legal system efficient in ensuring food safety. 
Many problems are rooted in the administration regime and China's priority of economic development. Following China's integration into the international community, food safety in China has already improved. However, a lot of work still needs to be done both in terms of legislation and implementation.

\section{NOTES}

1. Chen Xiwen, "Jiaru shijie maoyi zuzhi yu woguo nongye de fazhan" (Entering the WTO and the Development of Agriculture in China), Nongye jingji wenti (Economic Issues in Agriculture), Vol. 6, 2002, p. 5.

2. See http://www.moh.gov.cn/fzyjd/zgdt/120030903003.htm.

3. Food safety scandals published by the $\mathrm{MOH}$ and disclosed by the official media included the poisoned rice scandal: four rice factories in Guangdong province produced rice by polishing and whitening mouldy rice and mixing it with mineral oil. The hair solution scandal: six soy sauce factories in Chongqing used hair dissolved by hydrochloric acid and water in the production of a kind of blended soy sauce. (See Chongqing shangbao [Chongqing Commercial Newspaper], July 3rd 2003). The colouring use scandal: five rice noodle factories in Shandong province were found to be using a bleaching agent for industrial use only to whiten the rice noodles that they produced, which caused food poisoning in more than 87 students in four schools in Guangxi province. This agent was also found in a sugar factory in Zhejiang, capable of producing 50 tons of sugar a day. Fifteen tons of sugar treated with this bleaching agent were found in the factory. See "Who Can Protect Our Food Safety?", http://

www.cas.ac.cn/Htnl/Info/Newsl/006/00658.htm. Recently, a substandard milk powder produced in Anhui province was found to have led to the death and malformation of many babies.

4. In 2003 the State Administration of Industry and Commence published the top ten categories of complaints by consumers in 2002. Food safety was topmost. See http:// www.sanjiao.gov.cn/news/index.asp-18k-.

5. The exportation of tea, shrimps, honey, frozen chicken and beef from China to the EU met with difficulties in 2001 and 2002, see Shen Jifeng, "Chuqin chanpin zaoyu rushi xin tiaozhan" (Animal and Poultry Products Meet New Challenge of Entering WTO), in Chinese and Foreign Food, No. 12, 2002, p. 60; Ye Xingqing, "Ba lüse shipin chanye fazhan chengwei yige da chanye" (The Challenge of Increasing Green Food Production), Nongye jingji wenti (Economic Issues in Agriculture), Vol. 8, 2002, p. 3.

6. At the end of the 1950s and the beginning of the 1960s, most of the Chinese population experienced the Three-Year Famine (1959-61), or the "Three-Year Natural Disaster" as the government had called it. Several million people died of starvation. In 1959, 97.7 million people had to find some means in order to survive or leave their homes to look for food. In 1961, the last year of the disaster, 218 million people were affected. See Chen Donglin, “Three-year Disaster and the Great Leap Forward: A Historical Observation of the Relationship Between 'Natural Disaster' and 'Man-made Ruin”', http://www.ccrs.org.cn/big/snzrzhydyj.htm; Jin Hui, “Memorandum of 'Three- 
Year Natural Disaster"', http://www.chinafamine.org/famine/research/ro20901b.htm; Zhou Xiangling, "The Facts of the 'Three-Year Natural Disaster', The Biggest Lie of the Last Century", http://www.renminbo.com/rmb/articles/2003/9/13/27912b.htm.

7. In 1966 the government of China launched the 'Cultural Revolution'. See Jiang Ming'an (ed.), Administrative Law and Administrative Litigation Law, Peking University Publishing Company and High Education Publishing Company, 2002, Peking, pp. 53-63.

8. The 1995 Food Hygiene Law provides that food for infants and in hospitals must meet $\mathrm{MOH}$ standards. However, the MOH has not yet formulated any such standards.

9. The MOH is authorised by this law to govern food hygiene.

10. These new requirements are provided in Article 8, Chapter II.

11. There is a separate administrative measure for each of these categories of food.

12. See Kan Xuegui and Zhang Zhiqiang, "The Chinese Food Hygiene Regulations and Standards in Contrast to International Relevant Codes", Speeches in the Workshop on Food Safety, September 2002, Peking. http://www.ccpit-ssa.org.cn/chn/

workshopfoodsafe/9am/02-kanxuegui-chn.ppt

13. Ibid.

14. Ibid.

15. Ibid.

16. The volume of green food produced in China in 1998 was 56 times that in 1990. In $1998,1,018$ sorts of green food amounted to 8 million tons. In 2002, 3,046 sorts of green food amount to 25 million tons. See http://www.greenfood.org.cn/lsspjj.htm. See also Liang Zhichao and $\mathrm{Mu}$ Jianhua, "Fazhan lüse shipin-tigao nongchanpin zhiliang he anquan shuiping de youxiao tujing" (Developing Green Food-An Effective Way to Improve the Quality and Safety Level of Agricultural Products), in Zhongwai shipin gongye (Chinese and Foreign Food Industry), No. 5, 2003, p. 47. Yang Yishou, Zhongguo lüse jingii lüse chanye lilun yu shijian (The Theory and Practice of China's Green Economy and Production), published by China Mining University Press, 2002. 17. Sales of green food in 2001 amounted to 50 billion yuan (about US $\$ 6.05$ billion), of which US $\$ 0.4$ was from exports. In 2002 sales increased to 59.7 billion yuan (US $\$ 7.22$ billion), of which US $\$ 0.84$ billion was from exports. See Ye Xingqing, "Kuoda lüse shipin shengchan" (Broaden and Increase Green Food Production), in Nongye jingji wenti (Economic Issues of Agriculture), Vol. 8, 2002, p. 4.

18. Zhao Baowen, the deputy minister of the MOA, Speeches at the Section 7 of International Conference on the Safety of Transgenic Organisms. See http:// www.worldbiosafety.net/speeches/zhang\%20bao\%wen20\%(c).doc.

19. Ross Lester, et al., Genetic Modification in Agriculture: The Impact of China's Regulations on Foreign Trade and Investment, in China Law and Practice, November 2001, No. 9, Vol. 15, p. 20.

20. Xue Dayuan and Xia Youfu, "Shengwu anquan yidingshu dui zhuanjiyin shengwu maoyi de yingxiang ji duice" (Impacts of Biosafety Protocol on the Trade of Genetically Modified Organisms and Countermeasures in China), in Nongcun shengtai huanjing (Rural Bio-environment), Vol. 16 (4), 2000, p. 49.

21. http://www.monsanto.com.cn/monsanto/monsanto_china/jidai/ brief_intoduction.htm.

22. See supra note 18 .

23. http://www.monsanto.com.cn.

24. See supra note 18 . 
25. Ma Shuzhong and Huang Zuhui, "Zhongguo dui guoji maoyi zhong de zhuanjiyin nongchanpin biaozhi de guanli: xianzhuang, guize he jianyi" (The Administration of China on the Labelling of Transgenic Agricultural Products in International Trade: Current Status, Rules and Suggestions), in Nongye jishu jingji (Agricultural Technology and Economy) No. 1, 2002, p. 58.

26. Nanfang zhoumo, January 17th 2002.

27. No. 304 Order of the State Council of China in 2001.

28. The MOA decided to extend TMASTAP, http://www.agri.gov.cn/znfg/ t20021105_21882.htm. The US government urged China to extend these temporary measures to enable the exportation of US soya to China to continue. Former president Jiang Zemin planned to visit the United States on October 25th 2002. The Chinese government postponed the measures just before president Jiang Zemin left for the States because neither president wished to discuss this complicated issue during the meeting. See "China might postpone the temporary measure on the transgenic products", http://www.agri.gov.cn/gjdt/t20020927_9868.htm. See also http:// www.voa.gov/chinese/worldfocus/thur/09260203uschinatradegbtxt.htm.

29. "The MOA extended the Temporary Measures on the Administration of the Safety of Transgenic Agricultural Products”, see http://www.shac.gov.cn/nyxw/gnxw/ t20030718_76981.htm.

30. Ibid.

31. See "China might extend the temporary measure on the transgenic products", http://www.agri.gov.cn/gjdt/t20020927_9868.htm.

32. The work is as follows: the MOA should focus on reducing pesticide and chemical fertiliser pollution of agricultural products; GAQSIO should control product access to food markets; the MOH mainly checks hygiene in cafeteria, restaurants, hotels, eateries and producers of food additives; the SAIC should look over the licences of food producers and examine the quality of food on the market; the MOC should enhance its administration and direction in the circulation of food and perfect the food inspection system; the MPS should penalise those producing or selling sham or bad food, counterfeit food, and dangerous food; the CGA should administrate the import and export of food. See http://www.sfda.gov.cn. It is interesting to observe the role of the $\mathrm{MOH}$ in the programme launched by the SFDA. Although the MOH believes that it is the protagonist on the food safety stage, it seems to have only marginal responsibilities.

33. In March 1998, the National Environmental Protection Agency (NEPA) which was a sub-ministry, became the State Environmental Protection Administration (SEPA), with ministerial rank.

34. Report on the National Supervision Work in Hygiene in 2002 by the MOH, National Centre for Health Inspection and Supervision, http://jdzx.moh.gov.cn/WSZCYXX/ wsb2002wsjdtb.htm.

35. The Impact of Entering into the WTO on the Administration of the Products Relating to Health, National Centre for Health Inspection and Supervision, http:// jdzx.moh.gov.cn/xxyd/rswgjkdyx1.htm.

36. Action Plan on Food Safety, supra note 2.

37. Up to now there is no published list.

38. Soya, soy seeds, soy powder, soya oil, soya pieces are on the list.

39. Maize, maize seeds and maize powder are on the list.

40. Only cotton seeds must be labelled.

41. Tomatoes, tomato seeds and tomato jam are on the list. 
42. Rapeseed and rapeseed oil must be labelled.

43. The MOA had planned to inspect compliance with the Administrative Labelling Measures in spring 2003, but this inspection was postponed because of the spread of SARS. See "China will require transgenic labelling and carry out inspections", http:// www.agri.gov.cn/gndt/t20030421-77955.htm.

44. See http://www.moh.gov.cn/statistics/digest01/Ty5-86.htm.

45. See http://www.moh.gov.cn/statistics/digest03/t102.htm.

46. Ibid.

47. "Swill oil" (ganshui you) is collected from leftovers, thrown away by restaurants for example, and generally given to pigs. "Drain oil" (digou you) is collected from dishwater. In Peking, more than 50,000 hotels, restaurants and cafeterias dispose of about 1,600 tons of "swill oil" and 120 tons "drain oil" everyday. There have long been illegal oil producers who refine "swill oil" and "drain oil", which is sold on the open market and in small food shops or by foodstall-keepers. Some vendors mix this oil with oil refined normally to make the oil look normal and "fool" inspectors. See Wang Tie, Yan Zhinong, Yang Ying, Qi Yanjun (journalists from China Central TV) and Wu Chenguang, "The Black Curtain of Oil from Swill in Peking", in Nanfang zhoumou, September 25th 2003, p. 9.

48. This food safety plan "coincidently" ends in 2008. Since China was chosen to be host country of the 2008 Olympic Games, several working plans of the Peking government, such as green Peking, better traffic and clean air, set 2008 as their deadlines. This is a good example of China moving forward by integrating with international society. 49. Sun Zhenyu, Li Yuqin, Hexiaoli, Wangyan, "Jiaru WTO hou woguo nongyong huaxuepin wuran fangzhi duice yanjiu" (Studies on the Policy to Prevent and Clean Up Chemical Pollution in China's Agriculture after Entering the WTO), Nongye jingji wenti (Economic Issues in Agriculture), Vol. 4, 2002, p. 9.

50. Ibid.

51. Ibid.

52. Wang Zhizhen, "Shei lai baozheng women de shipin anquan" (Who is Ensuring the Safety of Our Food), Zhongwai shipin (Chinese and Foreign Food), No. 12, 2002, p. 59. Also see "Zenyang anquan de shiyong shucai" (How to Eat Vegetables Safely), in Shipin anquan renren youze (Everybody Has Responsibility for Food Safety), Feshan Agency of Hygiene, Guangdong, http://www.fshxyey.nease.net/wenzhai49.htm. Wang Zhizhen, "Guanxin shipin anquan bazhu rukouguan" (Caring About the Safety of Food), http:// www.bjkp.gov.cn/kxxf/k30327-04.htm.

53. Action Plan for Food Safety, supra note 2.

54. Ibid.

55. Report on the National Supervision of Hygiene in 2002 by the Ministry of Health, National Centre for Health Inspection and Supervision, http://jdzx.moh.gov.cn/ WSZCYXX/wsb2002wsjdtb.htm. This figure excludes restaurants and cafeterias.

56. See http://www.gxi.gov.cn/200307/2003729155748.htm.

57. "The Participation of Consumers and other Stakeholders in Food Safety Activities in China", the State Paper proposed by China, FAO/WHO Global Forum of Food Safety Regulations, Marrakech, Morocco, January 28th-30th 2002. This paper pointed out that "there is a need to explore better ways to communicate with those small and middlesized businesses" about risks in food. 
58. Report on the National Supervision of Hygiene in 2002 by the Ministry of Health, National Centre for Health Inspection and Supervision, http://jdzx.moh.gov.cn/ WSZCYXX/wsb2002wsjdtb.htm. 